ISSN 1518-3483

Licenciado sob uma Licença Creative Commons

\title{
Sobre a pesquisa em Modelagem na Educação Matemática brasileira ${ }^{1}$
}

\author{
A meta-understanding about the research in Mathematical \\ Modelling in Brazilian Mathematics Education
}

\begin{abstract}
Tiago Emanuel Klüber ${ }^{[a]}$, Dionísio Burak ${ }^{[b]}$
[a] Doutor em Educação Científica e Tecnológica pela Universidade Federal de Santa Catarina (UFSC), professor do Programa de Pós-Graduação em Educação (PPGE) e do Programa de Pós-Graduação em Ensino (PPGEn) da Universidade Estadual do Oeste do Paraná (Unioeste), Cascavel, PR - Brasil, e-mail: tiago_kluber@yahoo.com.br

[b] Doutor em Educação pela Universidade Estadual de Campinas (Unicamp), professor dos Programas de Pós-Graduação em Educação da Universidade Estadual de Ponta Grossa (UEPG) e da Universidade Estadual do Centro-Oeste (Unicentro), Guarapuava, PR - Brasil, e-mail: dioburak@yahoo.com.br
\end{abstract}

\section{Resumo}

Uma das principais demandas da pesquisa em Modelagem Matemática na Educação Matemática é o investimento em metaestudos de sua própria produção. Nesse contexto nossa investigação se sustentou e pôde ser empreendida sob a questão: como se mostra a pesquisa em Modelagem Matemática no Brasil, a partir dos trabalhos publicados no GT-10 do IV Seminário Internacional de Pesquisa em Educação Matemática?

1 Para fins textuais, em geral, utilizaremos apenas a expressão modelagem para nos referirmos à Modelagem Matemática na Educação Matemática. 
A abordagem de pesquisa, predominantemente qualitativa, inspirada na análise de conteúdo, orientou os procedimentos de análise e interpretação. Os resultados obtidos apontam para uma pluralidade de temas, métodos e autores que sustentam a comunidade de pesquisa. Essas pluralidades são discutidas e aprofundadas no contexto mesmo em que se mostraram e em alguns dos seus possíveis desdobramentos.

Palavras-chave: Metapesquisa. Pesquisa educacional. Educação. Ensino de ciências.

\begin{abstract}
One of the main research demands in mathematical modeling in mathematics education is the investment in metastudies of its own production. In this context our investigation was held and could be developed under the question: how is research in Mathematical Modeling presented in Brazil, from works published in the GT-10 of the IV International Seminar for Research in Mathematics Education? The research approach, which is predominantly qualitative, inspired by content analysis, guided the procedures for analysis and interpretation. The results point to a plurality of themes, methods and authors that support the research community. These pluralities are discussed and detailed in the same context they are shown and in some of its possible developments.
\end{abstract}

Keywords: Metasearch. Educational Research. Education. Science teaching.

\title{
Sobre a pesquisa: objetivo e contexto
}

Este artigo éum dos produtos de uma investigação mais ampla denominada "Modelagem Matemática no Brasil: na perspectiva da metacompreensão”, financiada pela Fundação de Apoio a Pesquisa do Paraná (FAP), Fundação Araucária. Ela se caracteriza como um metaestudo da área de Modelagem Matemática na Educação Matemática.

Investigações que se caracterizam como metaestudos se sustentam em argumentos que visam o fortalecimento dos campos de pesquisa em geral. Essas investigações se instauram no âmbito da comunidade quando os seus participantes buscam subsidiar as suas pesquisas de modo 
mais 'consciente' e 'seguro' (LESTER; LAMBDIN, 1997). Diante do exposto, podemos afirmar que o intuito de refletir sobre si mesma já alcançou o campo da Modelagem que busca se sustentar, avançar e se compreender (ALMEIDA, 2006; ARAÚJO, 2009; BARBOSA, 2007; BARBOSA; ARAÚJO; CALDEIRA, 2009; BICUDO; KLÜBER, 2011; BURAK et al., 2012; KLÜBER; BURAK, 2012; NISS, 2001).

Nesse contexto, de modo amplo, os principais objetivos da nossa investigação se centraram em explicitar, compreender e interpretar os significados da pesquisa brasileira sobre Modelagem Matemática na Educação Matemática. Estes são decorrentes, foram perseguidos e são apresentados neste artigo especificamente a partir da questão: como se mostra a pesquisa em Modelagem Matemática no Brasil, a partir dos trabalhos publicados no GT-10 do IV Seminário Internacional de Pesquisa em Educação Matemática? O GT-10 é específico sobre Modelagem Matemática na Educação Matemática. O evento foi escolhido por ser aquele de maiores ênfase e relevância no tocante à pesquisa para a Educação Matemática e, transitivamente, para o próprio Grupo de Trabalho.

O cunho compreensivo da questão nos inseriu numa tradição de pesquisa predominantemente qualitativa e nos aproximamos do objeto por meio de uma abordagem mista de investigação, muito semelhante à análise de conteúdo (BARDIN, 2011; FRANCO, 2005). Descrições detalhadas acerca da abordagem de pesquisa, dos procedimentos e dos instrumentos utilizados na investigação podem ser encontradas em Klüber e Burak (2012) e Burak et al. (2012).

Ainda que as descrições mais amplas sobre os aspectos metodológicos possam ser encontrados nos trabalhos supracitados, retomamo-as de modo sintético, para situar o leitor os procedimentos adotados e desenvolvidos.

\section{Sobre os procedimentos}

De modo geral, efetuamos uma análise estabelecida com critérios a priori a partir de categorias consideradas pertinentes à pesquisa, 
sem contudo considerá-las como estanques ou universais, são elas: 1) Autores de Modelagem Matemática; 2) Tipos de Análise; 3) Procedimentos e Instrumentos de coleta; 4) Delineamento de Pesquisa; 5) Autores outros; 6) Objetivos da Pesquisa em Modelagem Matemática; 7) Resultados de Pesquisa.

Destacamos, inicialmente, nos 11 (onze) artigos analisados, a partir da leitura, esses elementos de maneira literal exatamente como estavam registrados na publicação e, posteriormente, passamos a reuni-los em categorias mais abrangentes, com o auxílio do software de análise de dados qualitativos Atlas t.i que favorece a sistematização, organização, gerenciamento de projetos de pesquisa baseados na pesquisa qualitativa (KLÜBER; BURAK, 2012; WALTER; BACH, 2009).

Em suma, destacamos os dados em uma análise textual para em seguida passarmos a uma análise compreensiva em que os dados originais foram codificados para expressarem o nosso entendimento sobre ele. Por fim, para além das categorias efetuamos as interpretações sobre elas e para além delas, numa interlocução com a pesquisa que vem sendo realizada no campo.

Não nos preocupamos, no decorrer da pesquisa, em preestabelecer um referencial teórico para focarmos as categorias, pois assumimos que, a partir delas, podemos dialogar com distintas áreas que contribuem para uma interpretação mais ampla sobre o conteúdo explícito e latente em nossas análises.

Diante do exposto, apresentamos na seção a seguir os quadros analíticos estabelecidos, as descrições do conteúdo explícito e respectivas interpretações.

\section{Categorias, análises e interpretações}

As convergências dos significados que emergiram em nossas análises foram registradas em sete quadros que tratam das categorias mencionadas no início da seção anterior, em que descrevemos os procedimentos assumidos. Esses quadros são constituídos por três colunas, que dizem respectivamente: 1 ) aos nomes atribuídos às categorias, tanto 
aquelas definidas a priori como aquelas estabelecidas a posteriori; 2) aos documentos em que foram encontradas as citações - Pn, $\mathbf{P}$ significa o documento primário e $\mathbf{n}$ o número do documento; 3 ) ao número de trabalhos, dentre os 11 , em que as categorias foram citadas.

O Quadro 1 se refere aos autores de modelagem mais citados nos artigos publicados.

Quadro 1 - Autores de Modelagem Matemática

\begin{tabular}{llc}
\hline Autores & Documentos em que é citado & $\begin{array}{c}\text { Número de trabalhos } \\
\text { em que foi citado }\end{array}$ \\
\hline Almeida e outros & P2, P4, P5, P7, P8*, P10 & 6 \\
Araújo & P5, P7, P10, P11* & 4 \\
Barbosa & P1, P2, P3, P4, P5, P7*, P9, P10*, P11 & 9 \\
Barbosa, Caldeira e Araújo & P1, P4, P9, P11 & 4 \\
Bassanezi & P1, P3, P4, P6, P10 & 5 \\
Biembengut & P3, P6, P11 & 3 \\
Blum e outros & P1 & 1 \\
Borba & P1*, P5 & 2 \\
Burak e outros & P3*, P10 & 2 \\
Caldeira & P2*, P3 & 2 \\
Diniz & P1, P5 & 2 \\
Jacobini & P1, P5, P7 & 3 \\
Kaiser & P7, P10 & 2 \\
Malheiros & P1, P5 & 2 \\
Oliveira & P4, P7 & 2 \\
Outros & P1 ao P11 & 18 \\
\hline
\end{tabular}

Legenda: * = Artigo do próprio autor.

Fonte: Dados da pesquisa.

A análise do Quadro 1 permite afirmar que há um núcleo de autores de Modelagem citados em maior número e em diferentes artigos 
que é o caso de Almeida, Araújo, Barbosa, Bassanezi, Biembengut e Jacobini. Em primeiro lugar esclarecemos que esses autores são todos brasileiros. Essa constatação pode expressar uma interlocução interna significativa e, ao mesmo tempo, um diálogo minimizado com a comunidade internacional da pesquisa sobre Modelagem Matemática e Aplicações. Um dos motivos para essa utilização mais ampla de autores brasileiros pode estar associado ao que Barbosa (2001) diz sobre a tradição da pesquisa em Modelagem Matemática no Brasil. Ele afirma que ela é direcionada a aspectos sociais e críticos, diferentemente da tradição internacional que se assenta predominantemente em aspectos matemáticos e nas aplicações de matemática. Essa pouca interlocução pode ser facilmente visualizada pela presença de apenas duas referências internacionais que aparecem no Quadro 1, Kaiser e Blum e em apenas três trabalhos. Em termos teóricos e epistemológicos isso pode significar que há certa discrepância sobre aquilo que se produz em Modelagem Matemática no Brasil e a produção internacional, denotando preocupações e focos distintos. Pode expressar também a busca de uma demarcação de espaço e discussão própria sem recorrer à internacionalização da pesquisa.

Outro aspecto a ser observado é que os autores em geral citam os seus próprios trabalhos. Essa observação denota uma peculiaridade que parece ser algo comum em uma comunidade de pesquisa emergente e em consolidação. Em outras palavras, citar a si mesmo pode indicar a presença de novos resultados que decorrem de pesquisa própria o que justificaria plenamente a autocitação e se torna legítimo. Agregado a esse argumento, constatamos um número expressivo de autores citados que podemos denominar de novos pesquisadores. Além de o grande número de trabalhos impedir de citarmos os autores no escopo desse artigo, entendemos que estas produções apenas compõem o rol da produção atual sem a realização de pesquisas de fronteira, isto é, que realmente indiquem avanços ou rupturas com a produção até então estabelecida. Esse resultado converge para o apresentado por Bicudo e Klüber (2011), 
relativamente à dispersão de autores citados no âmbito da pesquisa sobre Modelagem.

A partir desse exposto consideramos pertinente avançar na compreensão dos significados de uma interlocução mais acentuada entre os autores brasileiros e estrangeiros que investigam sobre Modelagem Matemática. A título de exemplo, faz-se necessário compreender se esses autores são citados com vistas a sustentar a pesquisa, num sentido de filiação teórica, ou apenas como recurso a autores importantes, porém, sem a devida articulação.

O Quadro 2 diz dos tipos de análise empregados nas investigações.

Quadro 2 - Tipos de análise

\begin{tabular}{llc}
\hline Tipo de Análise & Documentos em que é citado & $\begin{array}{c}\text { Número de trabalhos em } \\
\text { que foi citado }\end{array}$ \\
\hline Análise de conteúdo explicitado & P4 & 1 \\
Análise indutiva & P11 & 1 \\
Codificação & P10 & 1 \\
Construção de quadros & P11 & 1 \\
Descrição & P10 & 1 \\
Grounded Theory & P7, P10 & 2 \\
Leisure & P4, P10, P11 & 3 \\
Triangulação & P5 & 1 \\
\hline
\end{tabular}

Fonte: Dados da pesquisa.

Por meio do Quadro 2, é fácil ver que os trabalhos P4, P5, P7, P10 e P11 explicitam procedimentos de análise empregados nos trabalhos, juntamente ao P3 que se caracteriza como ensaio. Diante disso, revela-se que os demais trabalhos não esclarecem tipos de análise que ensejam interpretação posterior.

Por meio dessa análise, compreendemos que há uma ausência em termos de apresentação dos procedimentos ou mesmo da concepção 
de análise e interpretação que são empregadas na pesquisa. De modo algum podemos afirmar que não existam. Entretanto, sua ausência indica que os pesquisadores e orientadores devem tomar atenção à explicitação de procedimentos de análise. A análise e a interpretação adequadas conferem a consistência e coerência necessárias à produção acadêmica. Portanto, é, no mínimo, salutar que os procedimentos sejam indicados no relatório de pesquisa ou artigo submetido à aceitação dos pares, mesmo quando remetem o leitor a outros trabalhos mais amplos como dissertações, teses ou pesquisas financiadas. Assim, há ao menos uma referência.

Em nosso entendimento, os trabalhos que indicam os procedimentos empregados tendem a ser mais consistentes e apresentar resultados mais significativos. Internamente é isso que se pode constatar nos artigos que esclareceram os procedimentos utilizados. Eles se mantêm alinhados aos objetivos propostos e não se perdem em considerações demasiadamente genéricas. Porém, há ainda que se tomar cuidado com o uso de determinadas metodologias que não são empregadas de modo pleno a atender a suas bases epistemológicas e mesmo regras de análise. Um exemplo é a menção ao uso da groundedtheory (teoria enraizada ou fundamentada nos dados), como é o caso dos artigos P7 e P10. Sem dúvida, os autores destes trabalhos afirmam que os procedimentos são apenas inspirados na teoria o que os protege e salvaguarda de um uso mais acurado. No entanto, esse sentido vago, que é atribuído à metodologia, pode conduzir a equívocos, principalmente para pesquisadores não iniciados.

A pesquisa qualitativa é um campo de múltiplas práticas interpretativas. Ela possui tensões e contradições em si mesma (DENZIN; LINCOLN, 2006). Desse modo, compreendemos que esses sentidos por vezes obscuros deságuam também no âmbito da pesquisa em Modelagem Matemática, como explicitamos nesta discussão.

Efetuadas as análises referentes aos tipos de análises empregadas nas pesquisas, passamos ao Quadro 3 em que apresentamos os procedimentos e instrumentos de coleta de dados. 
Quadro 3 - Procedimentos e instrumentos de coleta

\begin{tabular}{llc}
\hline Procedimento/Instrumento & Documentos em que é citado & $\begin{array}{c}\text { Número de trabalhos em que } \\
\text { foi citado }\end{array}$ \\
\hline Áudio-gravação & P10 & 1 \\
Entrevistas & P5, P10 & 2 \\
Notas de campo & P7 & 1 \\
Observação & P5, P7, P10 & 3 \\
Revisão bibliográfica & P6 & 1 \\
Questionário & P4, P5 e P6 & 3 \\
Relatórios e trabalhos escritos & P7 & 1 \\
Seleção de anais de eventos & P11 & P7 \\
Videogravação & & 1 \\
\hline
\end{tabular}

Fonte: Dados da pesquisa.

Conforme o Quadro 3 verifica-se que os trabalhos P5, P6, P7, P10 e P11 apresentam procedimentos ou instrumentos de coleta de dados ou recolha fontes. Esses trabalhos apresentam coerência interna entre o tipo de análise, os procedimentos empregados e a análise efetuada. Pode-se dizer que é da abordagem analítica assumida que os procedimentos ou instrumentos derivam ou são adequados. Há maior ocorrência, como se pode notar, do procedimento de observação, e dos instrumentos da entrevista e do questionário.

Em suma, é razoável esperar que os trabalhos recorram de modo mais acentuado ao procedimento de observação, uma vez que a maioria dos trabalhos é realizada em contexto de sala de aula, e a observação direta e participante do pesquisador é uma modalidade de procedimento bastante utilizada em pesquisas educacionais (VIANNA, 2005). Além disso, observa-se que, nos trabalhos em que os instrumentos foram indicados, há uma diversificação de instrumentos agregados à observação. $\mathrm{O}$ trabalho P5 valeu-se da observação, entrevista e questionário, mostrando plena compreensão da triangulação de dados. O trabalho P7, da observação acompanhada das notas de campo, relatórios e trabalhos escritos e videogravação. E o P6, de revisão bibliográfica e questionário. 
Uma diversificação de instrumentos subsidia uma análise mais profunda dos dados coletados. Esses trabalhos, voltados à pesquisa de campo expressam uma preocupação em cercear, de modo adequado, o objeto ao qual se reportam. O trabalho P11 foge a essas características, por ter coletado artigos publicados em anais de evento. Portanto, pode ser denominado de metaestudo com características próprias. Desse modo, o processo de coleta foi orientado pelo objeto de estudo que foi definido e pelas categorias previamente estabelecidas por literatura específica.

Porém, os demais trabalhos, exceto o $\mathrm{P} 3$, que se caracteriza como ensaio, não indicam claramente procedimentos ou instrumentos de coleta. Diante disso, emerge a necessidade de cuidado maior na caracterização dos processos de coleta de dados na pesquisa em Modelagem Matemática na Educação Matemática. Não explicitar os procedimentos de coleta pode ser apenas decorrente da escrita. Contudo, pode também indicar uma falta de compreensão global do desenvolvimento da pesquisa. De um lado, isso pode ser oriundo de pesquisas iniciais com pouco aprofundamento, o que é, até certo ponto, aceitável. De outro lado, tende a revelar que existem pesquisas pouco relevantes para a área, pelo modo como são relatadas.

O Quadro 4 versa sobre as categorias sobre a abordagem de pesquisa que é assumida na investigação.

\section{Quadro 4 - Delineamento de pesquisa}

\begin{tabular}{lll}
\hline Abordagem & Asserção compreensiva & Documentos em que é citado \\
\hline Qualitativo & $\begin{array}{l}\text { Pesquisas enunciadas sob } \\
\text { a abordagem de pesquisa } \\
\text { qualitativa }\end{array}$ & P5, P7, P10 \\
Quali-quantitativo & $\begin{array}{l}\text { Pesquisas enunciadas sob } \\
\text { a abordagem de pesquisa } \\
\text { quali-quantitativa } \\
\text { Pesquisas enunciadas como }\end{array}$ & P6 P3 e P11 \\
Pesquisa Teórica & $\begin{array}{l}\text { Pesquisas que não enunciam } \\
\text { abordagem }\end{array}$ & P1, P2, P4, P8, P9, \\
\hline Sem menção & & \\
\hline
\end{tabular}

Fonte: Dados da pesquisa. 
Por meio do Quadro 4 pode-se observar que seis artigos indicam claramente a sua opção, quais sejam: P3, P5, P6, P7, P10 e P11. Nos demais não aparece uma preocupação em esclarecer o posicionamento assumido. Os artigos que esclarecem a abordagem assumida são os mesmos que esclarecem procedimentos de coleta e análise de modo mais claro. Frente a isso, torna-se plausível inferir que a coerência interna passa pelo conhecimento de aspectos operacionais e também epistemológicos da produção do conhecimento. Essa discussão remete às condições e aos critérios de produção de conhecimento na pesquisa em Educação.

Dentre esses critérios, destaca-se a importância de que os trabalhos apresentem relevância científica e social, ou seja, estejam inseridos num quadro teórico em que fiquem evidentes a sua contribuição ao conhecimento já disponível e a opção por temas engajados na prática social. Há também uma cobrança para que as pesquisas tenham um objeto bem definido, que os objetivos ou questões sejam claramente formulados, que a metodologia seja adequada aos objetivos e os procedimentos metodológicos suficientemente descritos e justificados. A análise deve ser densa, fundamentada trazendo evidências ou as provas das afirmações e conclusões. Consideramos que deve ficar evidente o avanço do conhecimento, ou seja, o que cada estudo acrescentou ao já conhecido ou sabido. Esses seriam os critérios gerais, utilizados para julgar os trabalhos científicos [...] (ANDRÉ, 2001, p. 59).

No tocante aos artigos que não explicitam a abordagem efetuada, eles são relativamente mais frágeis ou ainda menos aprofundados do que aqueles que indicam. Nesse sentido, abre-se uma interpretação de que o domínio dos conceitos e noções de pesquisa descritos nos artigos, também para os artigos aqui analisados, favorece a produção de relatórios de pesquisa mais densos e com contribuições efetivas para a área de pesquisa. Essa fragilidade pode estar associada ao fato de ser difícil definir claramente o que é a pesquisa qualitativa. Ao fato de ela usar diferentes atividades interpretativas (DENZIN; LINCOLN, 2006). No entanto, para nós, isso não isenta a busca por um rigor que entendemos como a busca incessante por esclarecer o trajeto realizado durante a investigação (KLÜBER; BURAK, 2012). 
Percebe-se a predominância da abordagem qualitativa sobre a quantitativa. Assim, a tradição de pesquisa em Educação Matemática se confirma nas categorias que apresentamos. Em suma, as pesquisas que não dizem claramente a abordagem de pesquisa que assumiram, utilizam abordagens mistas. Estas se caracterizam pela articulação da literatura ou referencial assumido para oferecer explicações sobre os fenômenos estudados. Esse é um modo, também, legítimo desde que sejam explicitadas e evidenciadas as relações estabelecidas no âmbito interno da própria investigação.

Outro núcleo de análise que investigamos se refere aos principais autores que não são, especificamente, de Modelagem Matemática, conforme o Quadro 5.

Quadro 5 - Autores outros

\begin{tabular}{ll}
\hline Autores & Documentos em que é citado \\
\hline D’Ambrósio & P4, P6 \\
Morin & P3, P6, P11 \\
Dewey & P1, P5, P6 \\
Skovsmose & P2, P3, P10, P11 \\
\hline
\end{tabular}

Fonte: Dados da pesquisa.

De imediato, ao visualizar o Quadro 5, emerge a presença de poucos autores externos à área que sustentam as discussões realizadas no âmbito da pesquisa em Modelagem Matemática. Essa constatação corrobora com os resultados apresentados por Bicudo e Klüber (2011), quando apresentam, também D’Ambrósio e Skovsmose como os principais autores citados nas pesquisas sobre Modelagem Matemática. Sem dúvida, poderíamos empreender uma análise exclusiva a partir dos autores que são citados, de tal forma que avançássemos na compreensão de paradigmas teóricos em que as pesquisas e a própria Modelagem Matemática na Educação Matemática estão assentadas. No entanto, essa é uma investigação que neste momento não daríamos conta. 
Dentre os autores mais citados temos Ole Skovsmose que é o principal teórico da Educação Matemática Crítica²; Ubiratan D’Ambrósio ${ }^{3}$ considerado um dos precursores da Etnomatemática e educador matemático brasileiro renomado internacionalmente; Morin ${ }^{4}$ que fala sobre a teoria da complexidade; e Dewey ${ }^{5}$ conhecido por sua estreita ligação com a chamada Escola Nova.

No tocante à pesquisa, então, o que se ressalta é a grande variedade de autores que são utilizados para compreensão de temas educacionais. Bicudo e Klüber (2011) denominam essa grande variedade como uma dispersão. Diante disso emergem dois pontos de vista: não temos condições de afirmar que existe uma comunidade de pesquisa em torno de fundamentos mais ou menos similares e, de igual modo, não é possível afirmar que não exista. O que se torna arguível é a possibilidade de uma articulação com as escolas críticas e também de outras escolas, com outras denominações. Nesse sentido, há, ao menos, uma pluralidade de perspectivas teóricas que são agregadas às pesquisas em Educação Matemática. De um lado, esse é um movimento positivo tendo em vista que traz à tona a busca por subsidiar discussões sobre aspectos pouco aprofundados. De outro, ele facilita a perda de perspectiva ou a diluição, podendo acarretar a não concretização de linhas gerais que produzam resultados e ações práticas de médio e longo prazo. Enfim, uma atenção a esse ponto, em termos de debate, deve ser dada pelos pesquisadores de Modelagem Matemática na Educação Matemática.

No Quadro 6, apresentamos as categorias que se referem aos objetivos, objeto ou problemas de pesquisa que foram relatados nos artigos analisados.

2 Cf. SKOVSMOSE, O. Educação crítica: incerteza, matemática, responsabilidade. Trad. Maria Aparecida Viggiani Bicudo. São Paulo: Cortez, 2007.

3 Cf. D’AMBRÓsIO, U. Etnomatemática: elo entre as tradições e a modernidade. Belo Horizonte: Autêntica, 2005. (Tendências em Educação Matemática).

4 Cf. MORIN, E. Introdução ao Pensamento Complexo. Trad. Eliane Lisboa. Porto Alegre: Sulina, 2005.

5 Cf. DEWEY, J. Experiência e educação. Trad. Anísio Teixeira. 3 ed. São Paulo. Editora Nacional, 1979. 
Quadro 6 - Objetivos da pesquisa em Modelagem Matemática

\begin{tabular}{lll}
\hline Categoria & Asserção compreensiva & $\begin{array}{l}\text { Documentos em } \\
\text { que é citado }\end{array}$ \\
\hline $\begin{array}{l}\text { Metapesquisa em } \\
\text { Modelagem Matemática }\end{array}$ & $\begin{array}{l}\text { Esses objetivos são aqueles que descrevem, } \\
\text { destacam ou indicam o foco sobre a Pesquisa } \\
\text { em Modelagem Matemática ou sobre } \\
\text { aspectos que a constituem }\end{array}$ & P1, P11 \\
$\begin{array}{l}\text { Modelagem na formação } \\
\text { de professores }\end{array}$ & $\begin{array}{l}\text { Esses objetivos se voltam especificamente } \\
\text { para temas relativos à formação de } \\
\text { Professores na articulação com Modelagem } \\
\text { Matemática na Educação Matemática }\end{array}$ & P2, P4 \\
Articulação entre & $\begin{array}{l}\text { Esses objetivos se referem a aspectos } \\
\text { podéticos, como o trabalho que ocorre em } \\
\text { teorias }\end{array}$ & P5 P10, P6, P7, P8, P9, \\
& $\begin{array}{l}\text { Matemática que se desenvolvem em } \\
\text { contexto educativo }\end{array}$ & \\
\hline
\end{tabular}

Fonte: Dados da pesquisa.

Essas categorias se excluem entre si, pois indicam movimentos distintos, pois partem de pontos também distintos, naquilo que se refere à intenção e ao foco da pesquisa.

A primeira categoria, Metapesquisa em Modelagem Matemática, foi estabelecida por citações que expressam necessidades de mais pesquisas referentes à própria investigação. Um exemplo é esta que desenvolvemos, e agora apresentamos as análises e interpretações. Essa categoria ainda aponta necessidades de esclarecimentos concernentes aos termos e conceitos empregados de maneira tácita em diferentes concepções ou perspectivas de Modelagem Matemática, como é o caso da noção de interesse e também acerca dos aspectos epistemológicos e filosóficos que subsidiam as distintas concepções ou perspectivas. Sob uma ótica, os objetivos apresentados se mostram consistentes para o enfrentamento de problemáticas que ao longo da constituição da comunidade, não haviam sido enfrentadas. Eles apontam para um amadurecimento da área, em busca de consolidar resultados e subsidiar, de modo aprofundado, as suas investigações e os seus fazeres. De outra, esses objetivos indicam uma carência sobre essas reflexões, o que se desdobra em um convite à área 
para que se volte a si mesma, num intenso processo de diálogo, debate e redirecionamento.

A segunda categoria, Modelagem na Formação de Professores, que apareceu especificamente em dois trabalhos revela que há um investimento na compreensão dos impactos da implantação ou implementação da Modelagem Matemática para a formação continuada de professores, tanto em cursos de curta duração, como no âmbito da pós-graduação stricto sensu.

Esses objetivos ou problemas revelam que há diferenças significativas entre aquilo que se faz em Modelagem Matemática e a tradição predominante no âmbito da formação de professores (KLÜBER, 2012). Esses objetivos desvelam, ainda, que é necessário incentivar o desenvolvimento de pesquisas mais extensas, com acompanhamento e indagação dos fenômenos sociais que interferem junto à docência.

Ao buscar saber se os professores que assumiram a Modelagem Matemática em seus mestrados dão continuidade e mudam suas práticas para além do momento institucionalizado da pesquisa, tem-se uma nova faceta de investigação. Em outras palavras, solicita o enfrentamento de problemas de ordem cultural e social no âmbito da formação de professores que entram em conflito com os modos de conduzir Modelagem Matemática na Educação Matemática. Esses modos, para além de suas diferenças, possuem um caráter investigativo que rompe com os padrões estabelecidos nos processos escolares em geral e de formação de professores de Matemática. Indica, também, que há necessidade de investimento em pesquisas que apontem para ações pragmáticas com vistas ao enfrentamento das questões de resistência dos professores.

A terceira categoria, Articulação entre Modelagem e outras teorias, sobressai-se entre os objetivos, objetos e problemas identificados nos artigos analisados. As teorias agregadas à pesquisa são concernentes a processos cognitivos, didáticos, pedagógicos, tecnológicos, informáticos, sociais e culturais. Os processos cognitivos se pautam, por exemplo, na teoria interacionista de Vygotsky. Os processos didáticos, na transposição Didática de Chevallard. Os processos tecnológicos, na sua relação com educação a distância por meio da informática. E os processos sociais e culturais 
que aparecem quando dos usos da Modelagem Matemática, em sala de aula. Resultados semelhantes são encontrados em Bicudo e Klüber (2011).

Essa categoria revela que há uma ausência no âmbito da própria Modelagem Matemática na Educação Matemática. Dito de outro modo, revela que, mesmo que a Modelagem seja utilizada com finalidades educacionais, faz-se necessário recorrer a outras teorias que permitam lançar luz sobre os processos de aprendizagem ocorridos em seu interior. Revela, também, a busca por justificar determinados fazeres que são inerentes à prática de Modelagem Matemática. Em muitos casos, busca-se encontrar na Modelagem características correlatas às teorias empregadas (KLÜBER; BURAK, 2012).

Em diferentes artigos consegue coadunar distintas teorias no contexto da Modelagem Matemática. O que isso significa? Em nossa compreensão, é o dirigir-se à Modelagem com o olhar já preestabelecido teoricamente que permite visualizar aspectos da teoria. Um exemplo seria encontrar características interacionistas sem antes o docente buscar saber o significado dessa teoria para sua ação pedagógica. Agir assim é no mínimo ingênuo. Alguns trabalhos apontam outro caminho - o de assumir as teorias para realização da Modelagem. Nessa direção, busca-se constituir fundamentos para a ação com a Modelagem Matemática, o que tende a ser mais consistente. Portanto, afirmamos que ao usar uma teoria como guia de uma investigação, deve-se ter clareza que, de sua compreensão, ocorrerá um desdobramento na prática, porém, não em uma relação de causa e efeito.

Quadro 7 - Resultados de pesquisa

Continua

\begin{tabular}{lll}
\hline Categoria & Asserção compreensiva & $\begin{array}{l}\text { Documentos em que } \\
\text { é citado }\end{array}$ \\
\hline Demandas de pesquisa & $\begin{array}{l}\text { Esses resultados são aqueles que indicam } \\
\text { novos caminhos a serem enfrentados na } \\
\text { pesquisa da Modelagem Matemática na } \\
\text { Educação Matemática. }\end{array}$ & P1, P3, P4, P10, P11 \\
$\begin{array}{l}\text { Aprendizagem em } \\
\text { Modelagem }\end{array}$ & $\begin{array}{l}\text { Esses objetivos, apoiados em teorias de } \\
\text { Modelagem e outras teorias, tentam } \\
\text { evidenciar como ocorre e em que aspectos a } \\
\text { aprendizagem em Modelagem Matemática } \\
\text { se dá. }\end{array}$ & \begin{tabular}{l} 
P10, P7, P9, P8, P5, \\
\hline
\end{tabular} \\
\hline
\end{tabular}

Rev. Diálogo Educ., Curitiba, v. 14, n. 41, p. 143-163, jan./abr. 2014 
Quadro 7 - Resultados de pesquisa

Conclusão

\begin{tabular}{lll}
\hline Categoria & Asserção compreensiva & $\begin{array}{l}\text { Documentos em que } \\
\text { é citado }\end{array}$ \\
\hline $\begin{array}{l}\text { Modelagem em seus } \\
\text { aspectos próprios }\end{array}$ & $\begin{array}{l}\text { Esses resultados expressam compreensões } \\
\text { sobre a modelagem matemática, ora } \\
\text { baseados em resultados da literatura ora em } \\
\text { outras teorias. }\end{array}$ & P1, P8, P3, P4, P5, P2 \\
Status da pesquisa em & $\begin{array}{l}\text { Esses resultados evidenciam o status da } \\
\text { pesquisa em Modelagem Matemática no } \\
\text { Modelagem }\end{array}$ & P11 \\
$\begin{array}{l}\text { Brasil, bem como as suas demandas. } \\
\text { de professores }\end{array}$ & $\begin{array}{l}\text { Esses resultados articulam diferentes } \\
\text { aspectos da formação de professores e } \\
\text { Modelagem Matemática. }\end{array}$ & P4, P2, P3, P5 \\
Modelagem e outras & $\begin{array}{l}\text { Esses resultados revelam a busca de } \\
\text { articulação da Modelagem Matemática com } \\
\text { outras teorias de diversas áreas. }\end{array}$ & P9, P7, P6, P5, P3 \\
\hline
\end{tabular}

Fonte: Dados da pesquisa.

O Quadro 7 sintetiza os resultados apresentados nos artigos publicados no Seminário internacional de Pesquisa em Educação Matemática. Estabelecemos 6 categorias com as suas devidas convergências de significado, são elas: 1) Demandas de pesquisa; 2) Aprendizagem em Modelagem; 3) Modelagem em seus aspectos próprios; 4) Status da pesquisa em Modelagem; 5) Modelagem e formação de professores; 6) Modelagem e outras teorias. Para estas categorias, optamos por não interpretá-las uma a uma, já que serão explicitadas na relação com as demais categorias desenvolvidas ao longo do artigo.

Em nossa compreensão, destacaram-se resultados pertinentes para a área de Modelagem Matemática na Educação Matemática. Em geral, os resultados são consistentes. Desvelam-se resultados fundamentados nas metodologias e procedimentos empregados. Evidentemente, alguns resultados são apenas confirmações sobre aqueles já relatos na literatura. Contudo, eles não são predominantes, mostrando que ocorreu avanço nas temáticas investigadas. 
As demandas para a pesquisa em Modelagem Matemática centram-se em desenvolver metaestudos que esclareçam e orientem as futuras pesquisas. Os aspectos focados na aprendizagem ainda não indicam aprofundamentos. Isso, em nosso entendimento, se deve ao modo como os objetivos foram estabelecidos, buscando no interior da Modelagem de modo natural, algo que deveria ser introduzido em termos teóricos e práticos. O status da pesquisa representa um momento diferente do que agora apresentamos, ou seja, a área ainda reedita excessivamente temas de pesquisa. Porém, como já explicitamos, o próprio objeto de pesquisa revela, ao menos pontualmente, uma guinada nessa direção. No tocante à Modelagem e formação de professores os resultados são consistentes. Mostram que há resistência dos professores e apontam o contexto em que isso ocorre. Indicam, também, um mote a ser mais aprofundado acerca daquilo que acontece com o professor após o seu primeiro contato ou sua formação com Modelagem Matemática. A articulação da Modelagem com outras teorias mostra resultados por vezes excessivamente positivos. Porém, quando isso ocorre está vinculado a artigos com pouca clareza em termos metodológicos, principalmente ao que se refere aos procedimentos de análise empregados.

\section{Considerações}

Propusemo-nos a estudar o que se mostrava sobre a pesquisa nos artigos publicados no Grupo de trabalho sobre Modelagem Matemática, GT 10 pertencente ao IV Seminário Internacional de Pesquisa em Educação Matemática. Nossa pesquisa mostrou um panorama geral sobre as metodologias, autores de Modelagem, outros autores, objetivos e resultados de pesquisa. Depreendemos da investigação realizada que as pesquisas publicadas nesse grupo de trabalho apontam para a busca de mais consistência e coerência na condução de investigações na área.

Evidentemente alguns problemas emergiram, predominantemente, daquilo que diz respeito aos procedimentos ou instrumentos de 
análise e interpretação empregados. Esse fato pode estar atrelado à tradição de pesquisa qualitativa que como esclarecemos é predominante na tradição brasileira de pesquisa educacional. Nesse sentido, estudos sobre as teorias e abordagens de pesquisa, sejam qualitativas ou quantitativas, parecem se impor como demandas para pesquisa, acompanhando aquilo que foi argumentado por Klüber e Burak (2012).

Acompanhamos a reflexão de Denzin e Lincoln (2006, p. 17) de que, no âmbito das pesquisas qualitativas, "existe um compromisso no sentido do emprego de mais de uma técnica interpretativa em qualquer estudo". Desse modo, há uma necessidade de serem empregados métodos de coleta e análise apropriados ao estudo que é realizado, justamente para que ocorra a possibilidade de variar técnicas interpretativas sobre os dados. E isso, para nós, também decorre de uma clareza sobre o problema ou objeto de estudo situado.

\section{Referências}

ALMEIDA, L. M. W. Algumas reflexões sobre a pesquisa em Modelagem Matemática. In: SEMINÁRIO INTERNACIONAL DE PESQUISA EM EDUCAÇÃO MATEMÁticA, 3., 2006, Águas de Lindóia. Anais... Curitiba: SBEM, 2006. p. 1-12.

ANDRÉ, M. Pesquisa qualitativa em Educação: buscando rigor e qualidade. Cadernos de Pesquisa, n. 113, p. 51-64, jul. 2001.

ARAÚJO, J. L. Pesquisas sobre Modelagem em eventos científicos recentes de educação matemática no Brasil. In: SEMINÁRIO INTERNACIONAL DE PESQUISA EM EDUCAÇÃO MATEMÁTICA, 4., 2009, Taguatinga. Anais... Taguatinga: UCB, 2009. p. 1-14.

BARBOSA, J. C. Modelagem na Educação Matemática: contribuições para o debate teórico. In: REUNIÃO ANUAL DA ANPED, 24., 2001, Caxambu. Anais... Rio de Janeiro: ANPEd, 2001. p. 1-15. 
BARBOSA, J. C. Sobre a pesquisa em modelagem matemática no Brasil. In: CONFERÊNCIA NACIONAL SOBRE MODELAGEM NA EDUCAÇÃO MATEMÁTICA, 5., 2007, Ouro Preto. Anais... Ouro Preto: Universidade Federal de Ouro Preto; Universidade Federal de Minas Gerais, 2007. p. 82-103.

BARBOSA, J. C.; ARAÚJO, J. L; CALDEIRA, A. D. Modelagem Matemática: relatório das sessões do GT 10. In: SEMINÁRIO INTERNACIONAL DE PESQUISA EM EDUCAÇÃO MATEMÁTICA, 4., 2009, Taguatinga. Anais... Taguatinga: SBEM, 2009. Disponível em: <http://www.sbem.com.br/gt10/pdf/relatorio_ivsipem. pdf $>$. Acesso em: 9 jul. 2011.

BARDIN, L. Análise de conteúdo. 2. ed. rev. e ampl. Lisboa: Edições 70, 2011.

BICUDO, M. A. V.; KLÜBER, T. E. Pesquisa em modelagem matemática no Brasil: a caminho de uma metacompreensão. Cadernos de Pesquisa, v. 41, n. 144, p. $902-$ 925, set./dez. 2011.

DENZIN, N. K.; LINCOLN, Y, S. Introdução: a disciplinas e prática da pesquisa qualitativa. In: DENZIN, N. K. et al. O planejamento da pesquisa qualitativa: planejamentos e abordagens. Trad. Sandra Regina Netz. Porto Alegre: Artmed, 2006. p. 15-42.

BURAK, D. et. al. Sobre os objetivos de pesquisa concernentes à investigação em Modelagem Matemática na Educação Matemática. In: SEMINÁRIO INTERNACIONAL DE PESQUISA EM EDUCAÇÃO MATEMÁTICA, 5., 2012, Petrópolis. Anais... Petrópolis: Sociedade Brasileira de Educação Matemática, 2012. p. 1-18.

FRANCO, M. L. P. B. Análise de conteúdo. 2. ed. Brasília: Líber livro, 2005. (Série Pesquisa).

KLÜBER, T. E. (Des)Encontros entre a Modelagem Matemática na Educação Matemática e a Formação de Professores de Matemática. Alexandria: Revista de Educação em Ciência e Tecnologia, v. 5, n. 1, p. 63-84, maio 2012.

KLÜBER, T. E.; BURAK, D. Sobre a pesquisa qualitativa na Modelagem Matemática em Educação Matemática. Bolema: Boletim de Educação Matemática,v. 26, n. 43, p. 111-133, 2012. 
LESTER, F. K.; LAMBDIN, D. V. The ship to Theseus and other metaphors for thinking about what we value in mathematics education research. In: SIERPINSKA, A.; KILPATRICK, J. (Ed.). Mathematics education as a research domain: a search for identity: an ICMI Study. Dordrecht: Kluwer Academic Publishers, 1997. p. $415-425$.

NISS, M. Issues and problems of research on the teaching and learning of applications and modelling. In: MATOS, J. F. et al. (Ed.). Modelling and mathematics education - ICTMA 9: applications in science and technology. Chichester: Horwood Publishing, 2001. p. 72-88.

VIANNA, H. M. Pesquisa em educação: a observação. Brasília: Liber, 2005. (Série Pesquisa).

WALTER, S. A.; BACH, T. M. Adeus papel, marca-textos, tesoura e cola: inovando o processo de análise de conteúdo por meio do Atlas. In: SEMINÁRIOS DE EMPREENDENDORISMO E EDUCAÇÃO, 12., 2009, São Paulo. Anais... São Paulo: USP, 2009. p. 1-17.

Recebido: 25/07/2013

Received: 07/25/2013

Aprovado: 25/11/2013

Approved: $11 / 25 / 2013$ 
